Medical Research Archives

Volume 4

Issue 4.

Esophageal acid exposure analysis: with or without impedance?

\title{
Esophageal acid exposure analysis: with or without impedance?
}

*Authors

Daniela Jodorkovsky M.D,

Maria Kassab M.D., Orysia Kozicky B.A., Brad Dworkin M.D.

Sarah C. Upham Division of Gastroenterology and Hepatobiliary Diseases

New York Medical College

Corresponding author:

Daniela Jodorkovsky

40 Sunshine Cottage Drive, Valhalla, NY 10532

Phone: 914-594-2400

Fax: 914-594-2401

Jodorkovsky@gmail.com 


\title{
Medical Research Archives
}

Volume 4

Issue 4.

Esophageal acid exposure analysis: with or without impedance?

\begin{abstract}
$\underline{\text { Abstract }}$
Background: The data pertaining to esophageal acid exposure during multichannel intraluminal impedance-pH testing (MII-pH) may be analyzed by using all $\mathrm{pH}$ drops (simulating traditional $\mathrm{pH}$-monitoring) or analyzing only $\mathrm{pH}$ drops associated with impedance changes. It is unknown whether the acid exposure measurements would differ between these methods in a group of symptomatic patients.
\end{abstract}

Methods: We retrospectively evaluated MII-pH studies of patients from 2008 to 2013. Studies were re-analyzed so that acid measurements were obtained in two methods: 1 . Creating nonmealtime $\mathrm{pH}$ measurements related to retrograde impedance changes/bolus movements (" $\mathrm{pH}$ MII method") 2. Creating non-mealtime $\mathrm{pH}$ measurements anytime the $\mathrm{pH}$ fell below 4 regardless of impedance changes ("all-pH method”). Statistical analysis was performed using ttest, Fischer's test, and logistic regression.

Results: 121 patients were eligible. The mean percent total acid exposure time (4.05) was significantly higher in the all-pH method (vs. $1.63, \mathrm{p}=0.001$ ). The proportion of patients with abnormal acid exposure time (24.7\%) and DeMeester score $(24.8 \%)$ was higher in the all-pH method (vs. $8.3 \%, \mathrm{p}=0.001$; vs. $9.1 \%, \mathrm{p}=0.002)$. Compared to those without a hiatal hernia $(\mathrm{HH})$, more patients with a $\mathrm{HH}>2 \mathrm{~cm}$ had significant differences between analysis methods in upright (19.4\% vs. $5.56 \%, \mathrm{p}=0.03)$, recumbent $(29 \%$ vs. $6.67 \% ; \mathrm{p}=0.002)$, total time $(45.2 \%$ vs. $6.67 \%$, $\mathrm{p}=0.001$ ), and DeMeester score (35.5\% vs. 8.89\%; $\mathrm{p}=0.001)$. Adjusting for age, sex, and PPI usage, $\mathrm{HH}$ remained a significant predictor of whether results would differ (OR 12; CI 3.34-42.8 total exposure, OR 8.75; CI 2.36-32.5 DeMeester).

Conclusion: Analysis of esophageal acid exposure using all $\mathrm{pH}$ data detected more acid reflux than when incorporating impedance measures, particularly in those with a $\mathrm{HH}$. This finding may 


\section{Medical Research Archives}

Volume 4

Issue 4.

Esophageal acid exposure analysis: with or without impedance?

relate to small volume reflux. Therefore, analysis of all-pH reflux rather than just MII-pH should be considered in those patients with a $\mathrm{HH}$.

Keywords: gastroesophageal reflux; esophageal $\mathrm{pH}$ monitoring; hiatal hernia; $\mathrm{pH}$ impedence testing; gastric acid reflux 


\section{Medical Research Archives \\ Volume 4 \\ Issue 4.}

Esophageal acid exposure analysis: with or without impedance?

\section{Introduction}

In the evaluation of gastroesophageal reflux disease (GERD) symptoms, variables used to diagnose and quantify acid reflux include esophageal acid exposure as measured by percent time where the $\mathrm{pH}$ in the esophagus is less than 4, and a composite score called the DeMeester score. Esophageal acid exposure can be evaluated by catheter or wireless $\mathrm{pH}$ monitoring or multichannel intraluminal impedance-pH testing (MII-pH). MII testing detects reflux events by measuring the change in resistance to current flow when a retrograde bolus moves between two electrodes. With an affixed $\mathrm{pH}$ sensor, reflux events can then be characterized as being acidic $(\mathrm{pH}<4)$ or nonacidic $(\mathrm{pH}>4)$. Impedance-pH testing thus additionally detects weakly acidic or nonacid reflux (1). However both reflux monitoring methods have instances of false positive or missed acid reflux episodes. In $\mathrm{pH}$ monitoring, false positive drops in $\mathrm{pH}$ can be due to movement, respiration, electrode shift, or ingestion of acidic foods not flagged by patients during the study $(2,3)$. In control subjects, however, this phenomenon is rare (4). Conversely, a phenomenon of low volume acid reflux without related impedance changes has been described in patients with a hiatal hernia (5). Proximal migration of a subcardial acid pocket, or acid "film," may also be implicated in the pathophysiology of reflux but could be missed by MII if the volume is low $(6,7)$. Therefore, using MII-pH technology, it is unclear whether acid exposure should be analyzed separately (as if simulating traditional $\mathrm{pH}$ monitoring) or whether to incorporate the impedance data in acid analysis.

Proprietary software (Sandhill Scientific, Highland Ranch, CO, USA) offers the physician the option to analyze $\mathrm{pH}$ data using all non-mealtime $\mathrm{pH}$ drops $<4$, which simulates catheter based $\mathrm{pH}$ testing, 
Medical Research Archives

Volume 4

Issue 4.

Esophageal acid exposure analysis: with or without impedance?

or to include $\mathrm{pH}$ data only when it is associated with retrograde MII changes. It is unknown whether these two methods would yield significantly different test results in a population of symptomatic patients.

\section{Materials and Methods}

We identified patients who had already undergone MII-pH testing for the evaluation of gastroesophageal reflux disease (GERD) symptoms in our motility lab between the years 2008 to 2013 . Patients were excluded if they were less than 18 years of age, less than 23 hours of MII$\mathrm{pH}$ data was obtained, or insufficient background information was available. Demographics, endoscopy findings, presence of hiatal hernia $(\mathrm{HH})$ noted on EGD, manometry, or barium esophagogram, and proton pump inhibitor (PPI) usage during testing were obtained.

At our institution, MII-pH recordings are performed in a standardized fashion after an overnight fast using the Sandhill Scientific Sleuth Recorder. The $\mathrm{pH}$ electrode is positioned $5 \mathrm{~cm}$ above the lower esophageal sphincter which had previously been measured by high resolution manometry. Reflux in the impedance tracing is defined as retrograde bolus movement appearing as a $50 \%$ fall in impedance in a minimum of two consecutive impedance channels. Acid reflux events are defined as a concurrent drop in $\mathrm{pH}<4$. " $\mathrm{pH}-$ only" reflux is thus defined as a drop in $\mathrm{pH}<4$ without evidence of associated retrograde impedance change.

Once appropriate studies were retrospectively selected based on eligibility requirements, the MII-pH studies were reanalyzed, so that esophageal acid analysis was performed in two methods. The first created $\mathrm{pH}$ measurements only related to retrograde bolus movements, excluding meals ("pH-MII method"). The study was 


\section{Medical Research Archives \\ Volume 4 \\ Issue 4.}

Esophageal acid exposure analysis: with or without impedance?

then re-analyzed by creating $\mathrm{pH}$ measurements anytime the $\mathrm{pH}$ fell below 4 excluding meal times, simulating traditional pH-metry ( "all-pH method"). The automated analysis feature was initially used but tracings were manually reviewed by the principle investigator for accuracy.

The differences in total esophageal acid exposure, recumbent acid exposure, upright exposure, and composite DeMeester score between the two analysis methods were compared. Statistical analysis was performed using student t-test for continuous variables, Fischer's exact test for categorical variables, and multivariable logistic regression, using a $\mathrm{p}$ significance level of $<0.05$. The study was approved by the New York Medical College IRB.

\section{Results}

\subsection{Demographics:}

One hundred and twenty-five patients were identified, of which 121 were found eligible for analysis. Reasons for exclusion of 4 patients related to missing demographic data. The median age of the study population was 53 (range 21-92) and comprised 73 females, 48 males. The majority of the patients, $92(76 \%)$, endorsed typical esophageal GERD symptoms (heartburn, regurgitation), $22 \quad(18 \%)$ endorsed atypical extra-esophageal symptoms (cough, globus), and $7(6 \%)$ endorsed both typical and atypical symptoms. Seventy-two patients (59.5\%) were on PPIs during the MII-pH, 39 (32.2\%) were off PPI therapy, and PPI status was unknown in $10(8.3 \%)$. Thirty patients (32.8\%) were found to have a $\mathrm{HH}$ greater than $2 \mathrm{~cm}$ on endoscopy, barium esophagogram, or manometry (TABLE 1). The largest HH noted was $6 \mathrm{~cm}$.

\subsection{Esophageal acid exposure analysis:}


Medical Research Archives

Volume 4

Issue 4.

Esophageal acid exposure analysis: with or without impedance?

The mean percent time of acid exposure in the upright position (4.31), recumbent position (3.05) and total time (4.05) was significantly higher in the all-pH method compared to the pH-MII method $(1.92, \mathrm{p}=0.001 ; 1.07, \mathrm{p}=0.01 ; 1.63, \mathrm{p}=0.001$ respectively). Using a cutoff value of $>4.2 \%$, significantly more patients had an abnormal total esophageal acid exposure time (AET) in the all-pH method (24.8\%) compared to the pH-MII method $(8.3 \%$, $\mathrm{p}=0.001)$. The proportion of patients with abnormal AET in the upright and recumbent position showed a non-significant trend between the two methods of analysis (14\% vs. $6.6 \%, \mathrm{p}=0.09 ; 25.6 \%$ vs. $15.7 \%, \mathrm{p}=0.08$, respectively). The mean DeMeester score was significantly higher in the all-pH method (13.2) compared to the pH-MII method $(5.92, \mathrm{p}=0.002)$. The number of patients with an elevated DeMeester score using a cutoff of $>14.7$ was higher in the all-
$\mathrm{pH}$ method (24.8\% vs. 9.1\%, $\mathrm{p}=0.002)$

(TABLE 2).

\subsection{Influencing variables:}

To determine whether certain characteristics influenced the differences between the two methods of analysis, PPI use and presence of $\mathrm{HH}>2 \mathrm{~cm}$ was examined. A subgroup analysis of 111 patients with available PPI data was performed to determine the effect of PPI usage on analysis results. Patients on PPI therapy were not more or less likely to have significantly different results between the all-pH and $\mathrm{pH}-\mathrm{MII}$ method in measures of upright $\operatorname{AET}(5.56 \%$ vs. $10.3 \%, \mathrm{p}=0.45)$, recumbent AET ( $12.5 \%$ vs. $12.8 \%, \mathrm{p}=1)$, and total AET (11.1\% vs. $17.9 \%, \mathrm{p}=0.39)$ than those not on a PPI. PPI usage was not associated with significant changes in the DeMeester score using the two analysis methods $(11.1 \%$ of those on PPI had 
Medical Research Archives

Volume 4

Issue 4.

Esophageal acid exposure analysis: with or without impedance?

different results vs. $10.3 \%$ of those off PPI; $\mathrm{p}=1)$.

More patients with a $\mathrm{HH}$ had significantly different end results between the all-pH method and $\mathrm{pH}-\mathrm{MII}$ in measures of upright percent AET (19.4\% vs. 5.56\%, $\mathrm{p}=0.03)$, recumbent percent AET (29\% vs. 6.67\%; $\mathrm{p}=0.003)$, and total percent AET (45.2\% vs. $6.67 \%, \mathrm{p}=0.001)$ compared to patients without $\mathrm{HH}$. A greater proportion of patients with a $\mathrm{HH}$ had a significant change in their composite DeMeester score between all-pH and pH-MII methods (35.5\%) compared to patients without a $\mathrm{HH}(8.89 \%$; $\mathrm{p}=0.001)($ TABLE 3$)$.

Adjusting for age, sex, and PPI usage in this subgroup of 111 patients, $\mathrm{HH}$ remained a significant predictor of whether acid exposure results would differ using the all-pH method vs. pH-MII method of analysis in recumbent AET (OR 4.73; CI 1.41-15.9) and total AET (OR 12; CI 3.34-
42.8). However, $\mathrm{HH}$ had no effect on whether upright AET would be different between the two methods (OR 3.79; CI 0.853-16.9). Adjusting for age, sex and PPI usage, the odds of a significantly different DeMeester score were also high in the $\mathrm{HH}$ patients (OR 8.75; CI 2.36-32.5).

\section{Discussion:}

In the study providing normative data for 24 hour MII-pH testing, Shay S et al found that the incidence of "pH only" reflux, that is, acidic reflux episodes without associated impedance changes, was rare (2). This could lead to the implication that esophageal acid exposure would be similar using $\mathrm{pH}$ or MII-pH technology. However, patients with symptoms of GERD may show different characteristics. Indeed, Weigt et al recently demonstrated that in GERD patients with a $\mathrm{HH}$ there was a difference in median number of acid reflux episodes using MII$\mathrm{pH}$ or all-pH analysis (5). Disproving a 


\section{Medical Research Archives \\ Volume 4 \\ Issue 4.}

Esophageal acid exposure analysis: with or without impedance?

theory that the differences could be explained by artifact, the in vitro portion of the study found that acid infused via a smaller catheter did not lead to changes in the impedance sensors. Our study supports these findings; in our cohort of 121 patients, analyzing $\mathrm{pH}$ changes independent of impedance changes led to significantly more abnormal total esophageal acid exposure times and composite DeMeester scores.

The greater frequency in detecting acid reflux using the "all $\mathrm{pH}$ " method was magnified in those with a $\mathrm{HH}>2 \mathrm{~cm}$. The etiology of this finding could be explained by small amounts of acid (described as "acid pocket" or "acid film" in the literature) migrating proximally to the location of the $\mathrm{pH}$ sensor. Pandolfino et al found that this acid film was contained distal to the squamocolumnar junction in controls but migrated proximally in GERD patients (6). The acid film length/extent may be facilitated by a $\mathrm{HH}$; Beaumont et al scintigraphically showed that an acid film coated the esophagus in $\mathrm{HH}$ patients as far proximally as $5.6 \mathrm{~cm}$ above the squamocolumnar junction and that the position of the acid pocket above the diaphragm was a major risk factor for acid reflux (8).

There were several limitations to our study. The first is that while past studies were re-analyzed in a prospective fashion, some information, like PPI usage data was incomplete owing to the retrospective selection of our cohort. Other potential confounding variables, like severity of symptoms, body mass index, waist circumference, and race were not obtained due to the retrospective methodology and thus could not be controlled for. Finally, we assumed the presence of a $\mathrm{HH}>2 \mathrm{~cm}$ based on an endoscopy, manometry, or less commonly a barium esophagogram finding. 


\section{Medical Research Archives}

Volume 4

Issue 4.

Esophageal acid exposure analysis: with or without impedance?

As both manometry and endoscopy have been shown to be insensitive for $\mathrm{HH}$ detection compared to surgery, some patients who may have had a $\mathrm{HH}$ could have been missed. Ideally, all patients would have had both manometry and endoscopy results available to us to increase the sensitivity.
Despite these limitations, our study

is large in size and is the first to suggest that when analyzing MII-pH studies, distinct attention should be drawn to $\mathrm{pH}$-only reflux episodes, particularly in patients with hiatal hernia $>2 \mathrm{~cm}$. Our findings may be explained by the acid pocket (or "acid film"). 
Medical Research Archives

Volume 4

Issue 4.

Esophageal acid exposure analysis: with or without impedance?

\section{TABLE 1: Baseline characteristics}

\begin{tabular}{|ll|}
\hline Demographics & $\mathrm{N}(\%)$ \\
\hline Gender & \\
Male & $48(39.7)$ \\
Female & $73(60.3)$ \\
\hline PPI status & \\
& \\
On & $72(59.5)$ \\
Off & $39(32.2)$ \\
Unknown & $10(8.3)$ \\
\hline HH>2cm & \\
Yes & $30(24.8)$ \\
No & $91(75.2)$ \\
\hline
\end{tabular}

TABLE 2: Esophageal acid exposure analysis

\begin{tabular}{|l|l|l|l|}
\hline & $\begin{array}{l}\text { All-pH Method of } \\
\text { analysis }\end{array}$ & $\begin{array}{l}\text { pH-MII Method of } \\
\text { analysis }\end{array}$ & P Value \\
\hline $\begin{array}{l}\text { Abnormal upright AET } \\
\mathrm{N}(\%)\end{array}$ & $17(14)$ & $8(6.6)$ & 0.09 \\
\hline $\begin{array}{l}\text { Abnormal recumbent AET } \\
\mathrm{N}(\%)\end{array}$ & $31(25.6)$ & $19(15.7)$ & 0.08 \\
\hline $\begin{array}{l}\text { Abnormal total AET } \\
\mathrm{N}(\%)\end{array}$ & $\mathbf{3 0}(\mathbf{2 4 . 8})$ & $\mathbf{1 0}(\mathbf{8 . 3})$ & $\mathbf{0 . 0 0 1}$ \\
\hline $\begin{array}{l}\text { Elevated DeMeester score } \\
\mathrm{N}(\%)\end{array}$ & $\mathbf{3 0}(\mathbf{2 4 . 8})$ & $\mathbf{1 1}(\mathbf{9 . 1})$ & $\mathbf{0 . 0 0 2}$ \\
\hline
\end{tabular}


Medical Research Archives

Volume 4

Issue 4.

Esophageal acid exposure analysis: with or without impedance?

TABLE 3: Influence of Hiatal hernia on all-pH and pH-MII method of analysis

\begin{tabular}{|c|c|c|c|}
\hline & $\begin{array}{l}+\mathrm{HH}>2 \mathrm{~cm} \\
\mathrm{~N}=30\end{array}$ & $\begin{array}{l}-\mathrm{HIH}>2 \mathrm{~cm} \\
\mathrm{~N}=91\end{array}$ & P value \\
\hline $\begin{array}{l}\text { Upright AET of two methods } \\
\text { significantly different } \\
\mathrm{N}(\%)\end{array}$ & $6(19.4)$ & $5(5.56)$ & 0.03 \\
\hline $\begin{array}{l}\text { Recumbent AET of two methods } \\
\text { significantly different } \\
\mathrm{N}(\%)\end{array}$ & $9(29)$ & $6(6.67)$ & 0.002 \\
\hline $\begin{array}{l}\text { Total AET of two methods } \\
\text { significantly different } \\
\text { N(\%) }\end{array}$ & $14(45.2)$ & $6(6.67)$ & 0.001 \\
\hline $\begin{array}{l}\text { Significant change to DeMeester } \\
\text { score } \\
\mathrm{N}(\%)\end{array}$ & $11(35.5)$ & $8(8.89)$ & 0.001 \\
\hline
\end{tabular}


Medical Research Archives

Volume 4

Issue 4.

Esophageal acid exposure analysis: with or without impedance?

\section{$\underline{\text { References }}$}

1. Wang A, Pleskow DK, Banarjee S, et al. Esophageal function testing. Gastrointest Endosc. 2012; 76(2): 231-43

2. Shay S, Tutuian R, Sifrim D, et al. Twenty-four hour ambulatory simultaneous impedance and $\mathrm{pH}$ monitoring: a multicenter report of normal values from 60 healthy volunteers. Am J Gastroenterol. 2004;99(6):1037-43.

3. Sifrim D, Castell D, Dent J, et al. Gastrooesophageal reflux monitoring: review and consensus report on detection and definitions of acid, non-acid, and gas reflux. Gut. 2004;53(7):1024-31

4. Agrawal A, Tutuian R, Hila A, et al. Ingestion of acidic foods mimics gastroesophageal reflux during $\mathrm{pH}$ monitoring. Dig Dis Sci. 2005;50(10):191620
5. Weigt J, Malfertheiner P, et al. Small volume acid reflux in gastroesophageal reflux disease patients with hiatal hernia is only detectable by pH-metry but not by multichannel intraluminal impedance. Dis of the Esophagus. 2013;26(5):544-8.

6. Pandolfino JE, Zhang Q, Ghosh SK et al. Acidity surrounding the squamocolumnar junction in GERD patients: "acid pocket" versus "acid film". $A m \quad J$

Gastroenterol 2007;102:2633-2641.

7. Kahrilas PJ, McColl K, Fox, M, et al. The Acid Pocket: A target for treatment in reflux disease? Am J Gastroenterol 2013; 108: 1058-1064.

8. Beaumont H, Bennink R, de Jong J, et al. The position of the acid pocket as a major risk factor for acidic reflux in healthy subjects and patients with GORD. Gut 2010; 59: 441-451. 